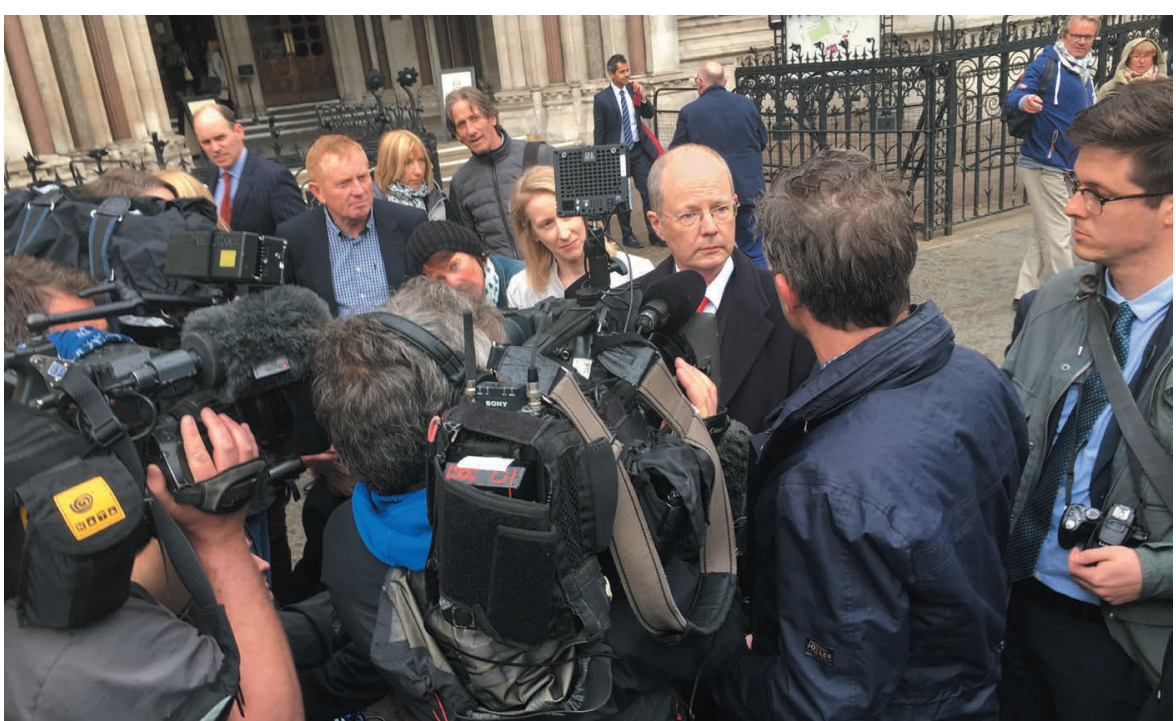

James Thornton (centre) of environmental law firm ClientEarth.

\title{
ENVIRONMENT
}

\section{Law for a healthy planet}

\section{Hari Osofsky draws lessons from the story of a pioneering environmental lawyer and his firm.}

\section{$\mathrm{T}$} hree stories intertwine in Client Earth, a study of the innovative European public-interest environmentallaw firm of that name, founded by James Thornton. The first is about how one person can make a difference through creative collaboration and persistence. The second is on the role of litigation in advancing social change. The third details how collaborative enforcement actions in multiple countries can build on one another to address immense planetary challenges, from climate change to pollution of air, water and soil.

Thornton, who co-wrote the book with his husband, author Martin Goodman, expresses his goal simply, as "systemic change to protect people and nature". In his view, "the most efficient way to achieve it is through law". He began his career as a litigator for the US Natural Resources Defense Council (NRDC) during the presidency of Ronald Reagan; he brought 88 citizens' suits against polluters. One of his important successes at the NRDC was a suit to enforce the US Clean Water Act against food company Gwaltney, for 666 days of violations as it discharged pollutants into a river. The court awarded a US $\$ 1,285,322$ penalty "to deter possible future violations."

For the past decade, Thornton has led ClientEarth's work in Europe, China and Africa. The book details some of the organization's notable environmental enforcement victories and what went into them. In 2015, ClientEarth succeeded in its challenge

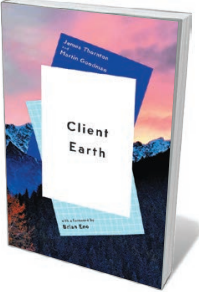

Client Earth JAMES THORNTON \& MARTIN GOODMAN Scribe: 2017

\section{burning of coal in domestic stoves.}

The book provides an unusual and muchneeded inside view of the development of environmental enforcement litigation, and its broader implications. It conveys the complex scales at which environmental protection works. Individual cases may be pinned to one location, but Thornton and Goodman reveal how the aim is to leverage them in a layered, strategic way with an eye to the long term. Goodman's chapters detail Thornton's journey and the evolution of ClientEarth as a complex dance among the diverse groups of people who shape transnational environmental policy, nature conservation and governance. Thornton's contributions explain his motivations and strategic decisions.

Each case, despite differences between legal systems, used law as a tool to enforce or develop environmental protections. A difficult question underlies this strategy: how can the transnational environmental movement - and specifically, a law firm - most effectively connect diverse problems in many places to broaden its impact? Scaling up is easiest across places with similar problems and systems, as shown by ClientEarth's efforts to address air quality across Europe, building from its UK victory to cases in Germany and plans for a further roll-out. Even there, the strategies must be different in each country.

To protect the planet more broadly, regional and national environmental enforcement movements must collaborate. Recently, Thornton worked with judges from China's Supreme People's Court to establish litigation cost structures that make it financially possible for plaintiffs to bring lawsuits. This builds on similar efforts he has made in Europe.

The story of ClientEarth's work raises crucial questions about the nature of transformative change. Is it brought about through major victories, like enforcing the EU Ambient Air Quality Directive? Is it through cumulative, highly specific cases, such as fights to reduce coal use in central European power plants?

These questions have also arisen in the United States, where most climate-change litigation takes place. There have been highprofile victories such as the 2007 Supreme Court decision Massachusetts v. Environmental Protection Agency, in which the court required the agency to regulate greenhouse gases or better justify its refusal to regulate; this provided the basis for the Barack Obama administration's regulation of emissions from vehicles and power plants. But numerous lower-profile cases have challenged coal projects and together had significant impact.

Strategic decisions also go beyond substantive framing of cases to addressing procedural barriers and navigating legal cultures. Thornton's focus on reducing litigation costs and building country-specific strategies reflects an understanding of these concerns.

Client Earth provides a tantalizing glimpse of how a variety of strategies can converge to create a global environmental enforcement effort. As we face issues such as the worsening impacts of climate change in the countries that are poorest and least able to adapt, international and national politics often fail to align to create progress. Elections since the 2015 Paris climate agreement reflect that. In such a context, the work of ClientEarth and other globally active law organizations that have advanced litigation is invaluable.

Hari Osofsky is Robins Kaplan Professor and director of the Energy Transition Lab at the University of Minnesota Law School in Minneapolis, and dean designate at Penn State Law and School of International Affairs in University Park, Pennsylvania. e-mail:hmo8@psu.edu

The author declares a conflict of interest; see go.nature.com/2q38bgs for details. 